\title{
Solitaire AB thrombectomy system: immediate results in 17 acute limb ischemia patients
}

\section{Yangyi Zhou}

Nanjing Medical Univisity https://orcid.org/0000-0002-4233-6819

Janesya Sutedjo

Nanjing First Hospital

\section{Maofeng Gong}

Nanjing First Hospital

\section{Jie Kong}

Nanjing First Hospital

\section{Boxiang Zhao}

Nanjing First Hospital

\section{Xu He}

Nanjing First Hospital

\section{Haobo Su ( zzyyyilu@foxmail.com )}

Nanjing First Hospital, Nanjing Medical University https://orcid.org/0000-0002-1713-289X

\section{Research}

Keywords: acute limb ischemia,endovascular therapy,Solitaire AB device

Posted Date: September 9th, 2020

DOI: https://doi.org/10.21203/rs.3.rs-60866/v1

License: (c) (i) This work is licensed under a Creative Commons Attribution 4.0 International License. Read Full License 


\section{Abstract \\ Background}

Solitaire AB stent was approved for mechanical thrombectomy for acute cerebral infarction.

\section{Objectives}

To present our initial experience regarding the efficacy and safety of mechanical thrombectomy using the Solitaire AB device for the treatment of acute limb ischemia (ALI).

\section{Patients and methods}

17 consecutive patients presenting with acute limb ischemia underwent endovascular therapy using the Solitaire AB device. Immediate angiographic results and early clinical outcomes are presented.

\section{Results}

Technical success was achieved in 15 patients (88.2\%). Recanalization of more than Ilb on the TILI scale was achieved for 15 patients. Mean times of thrombectomy attempts were 3 times. $41.2 \%(n=7)$ had excellent results. $41.2 \%(n=7)$ patients had good results. 2 had fair results, and 1 patient had a poor result. 30 days amputation rate was $6 \%(n=1)$. There was no death case.

\section{Introduction}

Acute lower limb ischemia (ALI) is a critical vascular emergency that both endangers the affected extremity and puts the patient's life at risk. ALI is associated with significant mortality (15-20\%) and an amputation rate reaching $30 \%[1]$. It is expected that a rapid increase in limb perfusion can decrease symptom severity and potentially prevent limb amputation, even death.

In 2012, Solitaire AB stent was approved by the US Food and Drug Administration (FDA) for mechanical thrombectomy for acute cerebral infarction.Several studies have demonstrated that Solitaire AB stent-assisted thrombectomy is a safe and effective treatment for acute cerebral infarction[2].

In this study we retrospectively analyzed the immediate efficacy of this therapy in a group of $17 \mathrm{ALI}$ patients.

\section{Materials And Methods}

\section{Study Design}

A retrospective review was conducted on patients treated by mechanical thrombectomy using the Solitaire AB device January between 2018 and November 2019.

The included patients were not consecutive, and other ALI cases were treated differently during this period. Off-label use of the Solitaire AB device was approved by the ethical committee of the hospital. Informed consent and explicit consent for the off-label use of the Solitaire AB device was obtained from the patient. Data were collected using electronic medical records.

\section{Patients}


17 patients were reviewed. The diagnosis was initially based on the clinical manifestations and previous disease history and was confirmed by duplex ultrasound.Among them, there were 5 males and 12 females. The mean age of the reviewed patients was 78 years (range,53-87 y). The degree of ischemic damage was classified according to the American Association of vascular surgery (SVS) / international society of cardiovascular surgery (ISCVS). The ischemic damage grade was as follows: 1 case at grade I, 9 cases at grade IIA, 7 cases at grade IIb. Patient characteristics, comorbidities, and medications are summarized in Table 1.

Table 1

Patient Characteristics and Risk Factors

\begin{tabular}{|ll|}
\hline Characteristic & Value \\
\hline Age, $y$, mean(range) & $78(53-87)$ \\
\hline Male sex, $\mathrm{n}(\%)$ & $5(29)$ \\
\hline Duration of symptoms & \\
\hline Less than $24 \mathrm{~h}, \mathrm{n}(\%)$ & $8(47)$ \\
\hline 1-7days, $\mathrm{n}(\%)$ & $8(47)$ \\
\hline 8-14days, $\mathrm{n}(\%)$ & $1(6)$ \\
\hline Rutherford Classification & \\
\hline I and IIA & $10(59)$ \\
\hline IIB & $7(41)$ \\
\hline Concomitant disease, $\mathrm{n}(\%)$ & \\
\hline Hypertension & $15(88)$ \\
\hline Diabetes mellitus & $6(35)$ \\
\hline Atrial fifibrillation & $13(76)$ \\
\hline Coronary artery disease & $7(41)$ \\
\hline Stroke & $6(35)$ \\
\hline
\end{tabular}

\section{Recanalization Procedure}

Endovascular recanalization was performed as follows.All procedures were performed via a femoral artery approach under local anesthesia.Diagnostic angiography of the affected limb was performed before the procedure to assess flow perfusion, by which Procedure-related information was obtained, including the diameter of the target vessel; length of embolic occlusion; and presence and severity of coexisting stenosis. A 6-F long sheath was introduced via a femoral approach. Under systemic heparinization, a 6-F guiding catheter (Mach1 Peripheral Guide Catheter; Boston Scientific, Marlborough, Massachusetts) was advanced near the proximal position of the occluded segment of the affected limb. A 2.8-F microcatheter (Progreat; Terumo Corporation, Tokyo, Japan) was introduced through the guiding catheter and then traverse the thrombus.After the vasculature distal to the thrombus was visualized on microcatheter angiograms, a Solitaire AB device was introduced through the microcatheter, and the device was deployed across the thrombus maintained in place for a few minutes ( 5 min) to allow device expansion.Then, the fully deployed Solitaire FR and the delivery microcatheter are gently pulled back together and recovered through the guiding catheter.During removal, a manual thrombus aspiration was performed using a $60 \mathrm{~mL}$ negative pressure syringe(VacLok; Merit Medical Systems, Inc., South Jordan, Utah).If occlusion persisted or if there was incomplete recanalization of the vessel, the microcatheter and stent were cleaned and reinserted for repeat thrombectomy.Solitaire $A B$ device uses up to 5 times. 
After procedure,catheter-directed thrombolysis was performed for cases which have thrombus remaining without contraindications for thrombolysis (bleeding tendency or active bleeding; severe hematological diseases; history of surgery or trauma within 2 weeks; cerebrovascular accident within 1 month).A S.M.A.R.T. CONTROL (Cordis, Milpitas, California) stent placement was performed in patients who had coexisting atherosclerotic stenosis narrowing $>50 \%$.

\section{Definitions}

Nowadays, the most widely accepted scoring system to grade the technical success of cerebral artery occlusion treated with thrombectomy recanalizing therapies is the Thrombolysis in Cerebral Infarction scale[3]. ALI has similar onset characteristics to acute ischemic stroke. Thrombolysis in Limb Infarction(TILI) scale was developed concerning the TICI scale for angiographic evaluation of thrombectomy recanalizing therapy for ALI. Specific grading standards are summarized in Table 1.

Technical success was defined as the successful completion of the procedure and TILI scale $\geq 2 b$.

Table 2

TICl scale

\begin{tabular}{|ll|}
\hline Grade & Description \\
\hline TILI 0 & no reperfusion \\
\hline TILI 1 & Unable to fill the distal vessels \\
\hline TILI $2 a$ & $>1 / 3$ of the vascular territory of the initially occluded vessel \\
\hline TILI $2 b$ & residual perfusion deficits in $\leq 1 / 3$ \\
\hline TILI 3 & complete reperfusion with filling of all distal branches \\
\hline
\end{tabular}

Results of treatment were rated excellent, good, fair, or poor as follows: excellent-the restoration of normal circulation and return of one or more pulses; good-the restoration of good circulation, without restoration of pulses; fair-the restoration of function, continued minor ischemic symptoms, no pulses; and poor-loss of function, amputation, rest pain and marked claudication, or death of the patient[4].

\section{Results}

The Solitaire AB device was successfully delivered intracranially in all 17 patients using standard endovascular techniques after arterial access was obtained via a femoral approach. Of all 17 patients, 3 lesions (17.6\%) were located in upper limbs, and 28 lesions (82.4\%) were located in lower limbs. with the diameter ranged from $3.76 \mathrm{~mm}$ to $5.04 \mathrm{~mm}$ the diameter ranged from $3.68 \mathrm{~mm}$ to $7.46 \mathrm{~mm}$. The diameter of the target vessels ranged from 3.68 to $7.46 \mathrm{~mm}$ (mean, $5.26 \mathrm{~mm}$ ), and the thrombus length ranged from 16 to $40 \mathrm{~mm}$ (mean, $25 \mathrm{~mm}$ ). In all patients, the presenting Thrombolysis in limb Infarction (TILI) perfusion category was 0 . Technical success was achieved in 15 patients (88.2\%). Recanalization of more than IIb on the TILI scale was achieved for 15 patients. For patients with infarct, the meantime of thrombectomy treatment time was 114 minutes. The mean times of thrombectomy attempts were 3. The Figure illustrates an example of such a successful thrombectomy procedure. After thrombectomy treatment, 1 patient who experienced unsuccessful thrombectomy underwent salvage stent implantation to obtain rapid flow restoration, 6 patients underwent CDT in which 1 patient received stent implantation to correct coexisting atherosclerotic stenosis.

41.2\%( $(n=7)$ had excellent results. $41.2 \%(n=7)$ patients had good results. 2 had fair results, and 1 patient had a poor result. 30 days amputation rate was $6 \%(n=1)$. There was no death case. 
Table 3

Procedure-Related Information and Procedure Outcomes

\begin{tabular}{|c|c|c|c|c|c|c|c|c|c|}
\hline Case & $\begin{array}{l}\text { Rutherford } \\
\text { Grade }\end{array}$ & $\begin{array}{l}\text { Embolism } \\
\text { location }\end{array}$ & $\begin{array}{l}\text { Target Vessel } \\
\text { Diameter(mm) }\end{array}$ & $\begin{array}{l}\text { Thrombus } \\
\text { Length }\end{array}$ & $\begin{array}{l}\text { Thrombectomy } \\
\text { Attempts }\end{array}$ & $\begin{array}{l}\text { TILI } \\
\text { Grade }\end{array}$ & $\begin{array}{l}\text { Technical } \\
\text { success }\end{array}$ & CDT & Stent \\
\hline 1 & Ila & RBA & 3.84 & 16 & 2 & $2 b$ & Y & $\mathrm{N}$ & $\mathrm{N}$ \\
\hline 2 & Ilb & LSFA & 5.22 & 24 & 3 & $2 b$ & Y & Y & $\mathrm{N}$ \\
\hline 3 & Ila & LPA & 3.88 & 16 & 3 & $2 b$ & Y & $\mathrm{N}$ & $\mathrm{N}$ \\
\hline 4 & Ila & LSFA & 5.54 & 27 & 2 & $2 b$ & Y & $Y$ & $Y$ \\
\hline 5 & Ilb & RPA & 5.52 & 18 & 3 & 3 & Y & $\mathrm{N}$ & $\mathrm{N}$ \\
\hline 6 & Ila & RBA & 3.76 & 22 & 3 & $2 b$ & Y & $\mathrm{N}$ & $\mathrm{N}$ \\
\hline 7 & Ila & LSFA & 6.08 & 28 & 5 & $2 b$ & Y & $Y$ & $\mathrm{~N}$ \\
\hline 8 & Ila & RSFA & 4.48 & 30 & 3 & 3 & Y & $\mathrm{N}$ & $\mathrm{N}$ \\
\hline 9 & Ilb & LSFA & 4.93 & 29 & 3 & $2 b$ & Y & $\mathrm{N}$ & $\mathrm{N}$ \\
\hline 10 & Ilb & LSFA & 5.34 & 22 & 3 & 3 & Y & $\mathrm{N}$ & $\mathrm{N}$ \\
\hline 11 & Ila & LPA & 5.44 & 18 & 3 & $2 b$ & Y & $\mathrm{N}$ & $\mathrm{N}$ \\
\hline 12 & Ilb & RSFA & 6.48 & 28 & 4 & $2 a$ & $\mathrm{~N}$ & $Y$ & $\mathrm{~N}$ \\
\hline 13 & Ilb & RAA & 5.04 & 36 & 5 & $2 b$ & Y & $Y$ & $\mathrm{~N}$ \\
\hline 14 & Ila & RSFA & 6.26 & 24 & 2 & $2 b$ & Y & $\mathrm{N}$ & $\mathrm{N}$ \\
\hline 15 & Ilb & RCFA & 7.46 & 40 & 3 & $2 a$ & $\mathrm{~N}$ & $Y$ & $\mathrm{~N}$ \\
\hline 16 & 1 & RPA & 3.68 & 19 & 3 & $2 b$ & Y & $\mathrm{N}$ & $\mathrm{N}$ \\
\hline 17 & Ila & LSFA & 6.47 & 30 & 4 & 3 & Y & $\mathrm{N}$ & $Y$ \\
\hline
\end{tabular}

\section{Discussion}

$\mathrm{ALI}$ is one of the most common acute and critical diseases with a high incidence, which has rapid progression. Without timely treatment, it will develop into ischemic necrosis with irreversible limb necrosis as well as significantly increased mortality. Early detection, diagnosis, and treatment are key factors that can improve the prognosis of ALI patients[5]. The restoration of blood flow to an ischemic vascular bed, that is, reperfusion, is a major therapeutic objective after ischemia of an organ or tissue, which can save limbs that are on the verge of ischemic necrosis, and reduce the disability and mortality in the later period. In 1963, Fogarty advocated the use of balloon catheter embolectomy for limb arterial embolization, which achieved satisfactory results. Compared with open thrombectomy, it has the advantages of less trauma, good patient tolerance, and lower postoperative mortality. However, Fogarty catheter embolectomy also has certain limitations: (1) arterial incision is required, and the surgical trauma is relatively large; the endometrium of blood vessels is easy to be damaged, which may cause vascular dissection or recurrent thrombo-occlusion. (2) The distal small arteries and branch vessels that cannot be reached by the balloon catheter often have residual thrombus after operation, resulting in a higher postoperative amputation rate. (3) Lack of guidance under X-ray perspective, and the removal of the plug has some blindness. CDT has become a firstline treatment option for acute limb ischemia[6, 7]. It is currently mainly used for patients with SVS / ISCVS Rutherford classification I, IIA, and IIB who have no thrombolytic contraindications. Compared with open surgery, it has less trauma and technical difficulties can be evaluated by dynamic angiography to evaluate the effect, the advantages of less vascular 
endothelial damage, less reperfusion injury, dissolving thrombus, and exposing potential stenosis of the artery at the same time. However, CDT also has certain limitations. Its progressive recanalization of blood vessels can not quickly remove thrombus and restore blood flow perfusion[8]. For SVS / ISCVS Rutherford IIB patients, if blood supply cannot be restored quickly, there will be post-limb motor function impairment and the possibility of blood necrosis, amputation, or even death. Therefore, PMT came into being, which can achieve rapid volume reduction of thrombus to reduce the time of symptomatic lower limb ischemia. Some studies have recommended PMT as a first-line treatment for ALI[9]. PMT currently applied to peripheral blood vessels mainly includes:large-lumen catheter aspiration, hemolytic thrombectomy such as Hydrolyzer from Cordis, Oasis and Possis AngioJet from Boston Scientific, and mechanical thrombectomy such as Amplatz thrombectomy and Straub Rotarex. Many studies have confirmed the safety of mechanical thrombectomy for the rapid restoration of blood perfusion in ALI. Stent thrombectomy is different from the above PMT. Its purpose is to reduce thrombus load and rapidly restore the blood flow, which helps to improve the efficacy of thrombolytic therapy. The Solitaire AB is a laser-cut, selfexpanding, and fully recapture able, split-design nitinol device which has been routinely used in mechanical thrombectomy for acute cerebral infarction. In addition to craniocerebral blood vessels, Solitaire AB stent has also been used to retrieve superior mesenteric artery embolism[10]. Studies have shown that for acute ischemic stroke, the vascular recanalization rate and prognosis of stent thrombectomy are significantly better than those of non-stent PMT in all PMT procedures[11].

In addition to the advantages of less trauma and simple operation, Solitaire AB stent thrombectomy also has the following advantages: (1) It can be directly released at the thrombus site to play a role of "tunnel", it can quickly open blood vessels to reconstruct blood flow, and improve the state of limb ischemia in the short term. (2) Its delivery system can achieve the distal arteries of the extremities, such as the dorsal foot arteries, plantar arteries, or palm arterial arches of the upper limbs to treat the emboli effectively. (3) It can be completely released and recovered many times. Repeated use can improve the thrombus clearance rate and reduce operating expenses.

We combined Solitaire $A B$ stent removal with thrombus aspiration to reduce distal embolism and improve the recanalization rate. However, a distal embolism still occurred in the seventh case, which eventually led to amputation. Therefore, in later cases, a spider arterial umbrella device was pre-inserted before stent removal to avoid distal embolism.

Acute arterial embolism is mostly old cardiogenic thrombus or sclerotic plaque blocking the blood flow after shedding into the blood vessel which secondary to proximal or distal thrombus. Such emboli is not sensitive to thrombolytic agents. Solitaire $A B$ stent thrombectomy has a good effect on fresh thrombi secondary to this type of emboli. The stent thrombectomy can completely remove the emboli and the secondary thrombus $24 \mathrm{~h}$ after the onset of the disease. Combining anticoagulation and arterial thrombolysis can completely dissolve the remaining thrombus in the blood vessel. However, the stent was originally designed for intracranial blood vessels. The diameter is only $4 \mathrm{~mm}$ and $6 \mathrm{~mm}$, and the length is only 15, 20, and $30 \mathrm{~mm}$. The friction between the blood vessel wall and the blood clot causes the blood clot to adhere to the wall of the stent to be retrieved. If the diameter of the embolized blood vessel is larger (>6 mm), the use of the Solitaire stent to remove the embolus will be greatly weakened or even ineffective because the stent is not completely adhered to the wall.

This study has several limitations. First, this is a retrospective study of a single, two-year study of a small number of patients. Second, this study cannot evaluate the importance of stent removal and thrombus aspiration in this combined technique. Because this study is a small preliminary retrospective, the results should be interpreted with caution. Additional comparative studies are needed to determine the role of stent removal and thrombus aspiration in this combined technique.

\section{Conclusions}

In short, Solitaire AB stent mechanical thrombus removal combined with thrombus aspiration is a simple and effective method for the treatment of acute limb ischemia. It has the advantages of minimally invasive, safe, and few complications. The exact effect of this combined technique on acute limb ischemia It should be further evaluated through prospective largescale studies. 


\section{Abbreviations}

ALI: Acute lower limb ischemia; TICl: Thrombolysis in Cerebral Infarction scale; TILI: Thrombolysis in Limb Infarction.

\section{Declarations}

\section{Acknowledgements}

Not applicable.

\section{Funding}

None.

\section{Availability of data and materials}

Data sharing not applicable to this article as no datasets were generated or analyzed during the current study. If you do not wish to publicly share your data, please write: "please contact author for data requests."

\section{Author's contributions}

Contributed $100 \%$ by the corresponding author. The author read and approved the final manuscript.

\section{Conflicts of interest}

There are no conflicts of interest existing.

\section{References}

1. Howard DPJ, Amitava B, Fairhead JF, et al. Population-Based Study of Incidence, Risk Factors, Outcome, and Prognosis of Ischemic Peripheral Arterial Events: Implications for Prevention. 2015. 132(19): p. 1805-1815.

2. Dorn F, Stehle S, Lockau H, et al. Endovascular treatment of acute intracerebral artery occlusions with the solitaire stent: single-centre experience with 108 recanalization procedures. Cerebrovasc Dis. 2012;34(1):70-7.

3. Dargazanli C, Fahed R, Blanc R, et al. Modified Thrombolysis in Cerebral Infarction 2C/Thrombolysis in Cerebral Infarction 3 Reperfusion Should Be the Aim of Mechanical Thrombectomy: Insights From the ASTER Trial (Contact Aspiration Versus Stent Retriever for Successful Revascularization). Stroke. 2018;49(5):1189-96.

4. Hallman GL, Billig DM, Beall AC, et al. Surgical Considerations in Arterial Embolism Archives of SURGERY. 1966;46(4):1013-20.

5. Dormandy J, Heeck L, Vig S. Acute limb ischemia. Semin Vasc Surg. 1999;12(2):148-53.

6. Graor R, Comerota A, Douville Y, et al. Results of a Prospective Randomized Trial Evaluating Surgery Versus Thrombolysis for Ischemia of the Lower Extremity The STILE Trial. 1994. 220(3): p. 251.

7. Weaver FA, Comerota AJ, Youngblood M, et al. Surgical revascularization versus thrombolysis for nonembolic lower extremity native artery occlusions: results of a prospective randomized trial. The STILE Investigators. Surgery versus Thrombolysis for Ischemia of the Lower Extremity. J Vasc Surg, 1996. 24(4): p. 513 - 21; discussion 521-3.

8. Gerhard-Herman MD, Gornik HL, Barrett C, et al. 2016 AHA/ACC Guideline on the Management of Patients With Lower Extremity Peripheral Artery Disease. Circulation. 2016;135(12):e726.

9. Leung DA, Blitz LR, Nelson T, et al. Rheolytic Pharmacomechanical Thrombectomy for the Management of Acute Limb Ischemia: Results From the PEARL Registry. J Endovasc Ther. 2015;22(4):546-57.

10. Shi Y, Gu J, Chen L, et al. Mechanical Thrombectomy Using the Solitaire AB Device for Acute Embolic Mesenteric Ischemia. J Vasc Interv Radiol. 2019;30(1):43-8. 
11. Hentschel KA, Daou B, Chalouhi N, et al. Comparison of non-stent retriever and stent retriever mechanical thrombectomy devices for the endovascular treatment of acute ischemic stroke. J Neurosurg. 2017;126(4):1123-30.

\section{Figures}
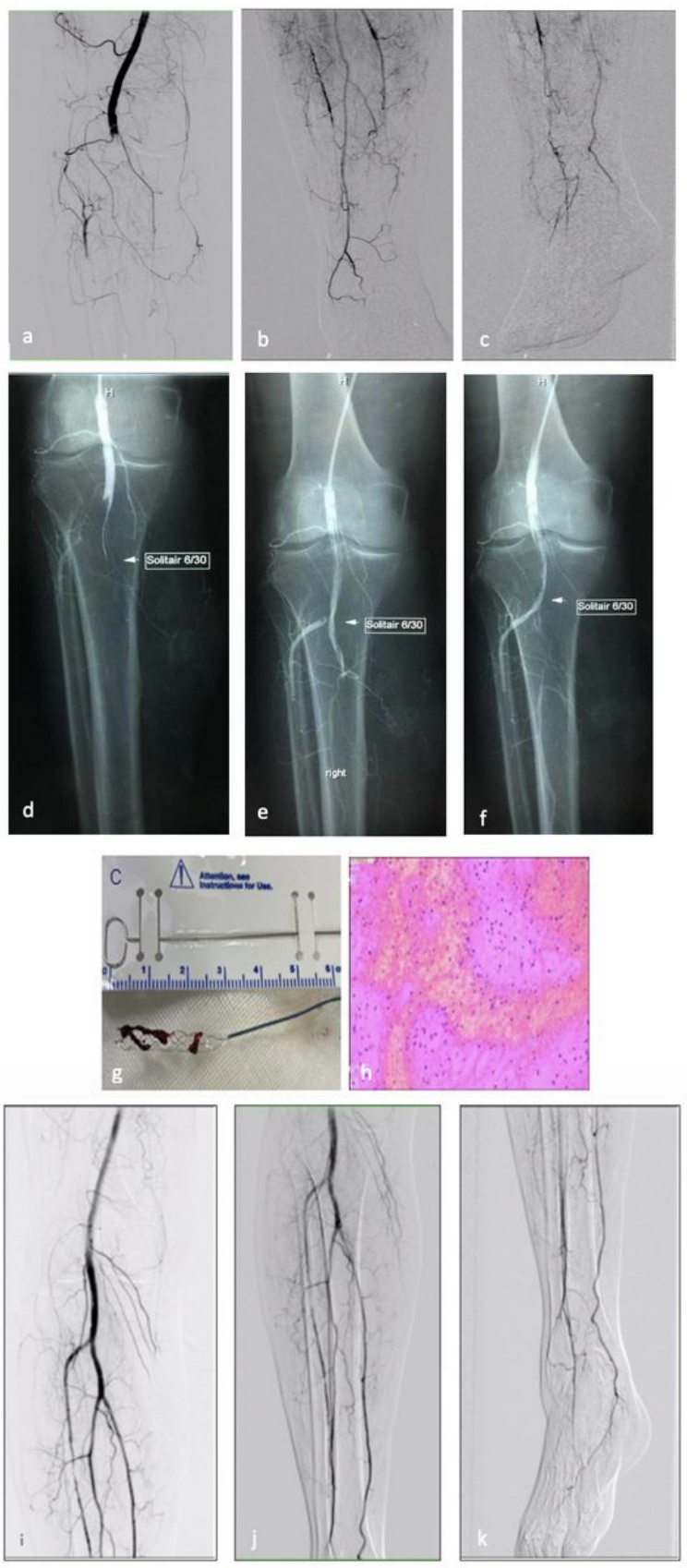

\section{Figure 1}

A patient with acute limb ischemia was successfully treated with the Solitaire AB device.( a-c) A 66-year-old woman experienced right limb pain for 72 hours, and acute embolic occlusion at right popliteal artery was confirmed by duplex ultrasound. Diagnostic angiography of right limb. (d-f)The Solitaire AB device was deployed across the thrombus maintained in place for a 5 minutes. (g) Clots retrieved by Solitaire AB device are shown. (h) Pathology suggested mixed thrombus. (i-k) A third pass resulted in complete recanalization of the RPA and its branches(Thrombolysis in Limb Infarction 3).

\section{Supplementary Files}


This is a list of supplementary files associated with this preprint. Click to download.

- GraphicalAbstract.jpg 